\title{
The Effectiveness of Learning Arabic Vocabulary Using Multimedia Technology
}

\author{
Rahmaini $^{1}$, and Muhammad Irwan Padli Nasution ${ }^{2}$ \\ \{irwannst@uinsu.ac.id ${ }^{1}$ \} \\ Universitas Islam Negeri Sumatera Utara ${ }^{1,2}$
}

\begin{abstract}
Arabic is an international language, so it is also important to be able to learn it. But learning Arabic is certainly not as easy as learning Indonesian which is our mother tongue. The uniqueness of Arabic also lies in its script which is not a Latin letter and how to read it also requires special knowledge. Thus, in order to facilitate learning it needed aids as a medium of learning. Development of learning media with Information Communication and Technology (ICT) utilization can be developed multimedia-based learning media. One of the developments in Multimedia technology is able to give a big and deep impression in the field of communication and education. In this study will be compared how the learning outcomes of students who learn without the help of multimedia technology by using multimedia learning media tool. Thus, it will be known how effective the use of learning media with multimedia technology especially for Arabic lessons.
\end{abstract}

Keywords: Arabic, learning, effective, multimedia.

\section{Introduction}

The United Nations (UN) has decided to make Arabic one of the official languages of the United Nations on December 18, 1973. Arabic is accompanied by 5 other official languages of the United Nations (English, Chinese, French, Russian and Spanish). When the official UN meeting was held, representatives of the countries involved gathered in one large room and they delivered various ideas using the 6 official languages. The determination of Arabic as the official language of the United Nations on December 18, 1973 inspired Morocco and Saudi Arabia to propose to UNESCO so that the date is celebrated as World Arabic Language Day in 2010. The purpose of this memorial is as a form of promotion of multilingualism and cultural diversity. Since the establishment of Arabic as the official language of the United Nations, people who want to learn Arabic are increasing every year. As for learners of Arabic language and literature, the inauguration on December 18, 1973, seemed to be a breath of fresh air to expand the reach of working in a variety of new sciences. The implementation of World Arabic Language Day by UNESCO actually awakened various parties in the world that many of the vocabulary from Arabic turned out to have merged with other foreign languages such as English. Many young people are competing to learn Arabic culture and its language and culture because the image of Saudi Arabia itself is so good in the eyes of the Indonesian people. Learning Arabic and enriching vocabulary in Arabic makes it easy to learn Arabic. Various vocabulary related to everyday conversation is divided into various types ranging from the name of the day, objects, or others. It's the same when learning English. By memorizing the various vocabulary, you will certainly find it easy to learn Arabic so that you 
will be more proficient in Arabic. In a teaching and learning process, two very important elements are teaching methods and teaching media. These two aspects are interrelated. Learning media are a physical means to convey learning content / materials such as: books, films, videos and so on (Briggs, 1977). Meanwhile, National Education Association (1969) revealed that instructional media is a means of communication in print and in-kind forms, including hardware technology. From the three opinions above concluded that the learning media is everything that can channel messages, can stimulate students' thoughts, feelings, and wishes so that they can encourage the creation of learning processes in students. The evolution of technology that is increasingly developing has given effect to humans to change their lifestyle so that they can better adapt to the existing technological conditions. Technological developments, especially Information and Communication Technology have benefited from the development of learning media used both in theory and practice learning. Information and Communication Technology (ICT) can be used as learning aids, and can even replace the role of the teacher in learning. Information and Communication Technology In Education. ICT stand for information and communication technologies and is defined, as a "diverse set of technological tools and resources used to communicate, and to create, disseminate, store, and manage information." Development of learning media with Information Communication and Technology utilization can be developed multimedia-based learning media. One of the developments in Multimedia technology is able to give a big and deep impression in the field of communication and education. In line with Industry 4.0, at present the development of ICT makes producers compete to produce products that are mobile so that they are more flexible and can be carried everywhere. Thus slowly the use of Personal Computers has slowly begun to decline. Urban communities are increasingly busy and have high mobility so they certainly prefer mobile technology. The mobile era also presents tablets, as one of the sophisticated technology devices and has many uses. Smaller tablet sizes than laptops also cause some people to prefer to use tablets. In addition to laptops and tablets, there are also technologies that have progressed very rapidly now, namely gadgets or smartphones. Today, with a small size, smartphones are increasingly sophisticated and have various applications that make it easier for humans to carry out various communication activities. Using of learning media in the teaching and learning process needs to be planned and systematically planned so that the learning media are effective for use in the teaching and learning process. Effectiveness is often closely related to the comparison between the level of achievement of a goal and a predetermined plan, or the comparison of real results with the planned results. The effectiveness can be used as a measuring tool to measure educational success. The indicator that is used as a benchmark in stating that the teaching and learning process is said to be successful, is the absorption capacity of the learning material taught to achieve high achievement, both individually and in groups that are defined in the teaching objectives.

\section{Multimedia Based Learning}

Understanding learning media are all teaching tools that are used to help convey the subject matter in the teaching and learning process so as to facilitate the achievement of the objectives of the learning objectives that have been formulated. Association for Educational Communications and Technology. The Association for Educational Communications and Technology (AECT) provides a definition that is everything that people use to channel messages and can stimulate students to learn more. Learning media used in learning activities 
can influence the effectiveness of learning. In the beginning, the learning media only functioned as a teacher's tool to teach which was used as a visual aid. Around the middle of the 20th century visual utilization efforts were complemented by the use of audio equipment, so audio-visual aids were born. In line with the development of ICT, especially in the field of education, currently the use of assistive devices or learning media is becoming increasingly widespread and interactive, such as the existence of computers and the internet.

Learning media have several functions, including: (1) Learning media can overcome the limitations of experience possessed by students. The experience of each student varies, depending on the factors that determine the wealth of a child's experience, such as the availability of books, opportunities for travel, and so on. Learning media can overcome these differences. If students are not likely to be brought to the object directly studied, then the object is brought to the students. The object in question can be in the form of real, miniature, models, and forms of images that can be presented in an audio-visual and audible manner; (2) Learning media can exceed the limits of classrooms. Many things that cannot be experienced directly in the classroom by students about an object, which is caused, because: (a) the object is too large; (b) the object is too small; (c) objects that move too slowly; (d) object that move too fast; (e) objects that are too complex; (f) object that sound too smooth; (f) objects contain dangerous and high risk. Through the use of appropriate media, all objects can be presented to students; (3) Learning media allow direct interaction between students and their environment; (4) Media produces uniformity of observation; (5) The media can instill basic concepts that are true, concrete, and realistic; (6) The media evokes new desires and interests; (7) The media evokes motivation and stimulates children to learn; (8) The media provides an integral / comprehensive experience from the concrete to the abstract. In line with the development of ICT so that the mindset of teachers must be changed to a constructive learning system replaced by utilizing ICT. The development of science and technology for media use, both visual, audial, projected still media and projected motion media can be done together and simultaneously through a single tool called Multimedia. Multimedia comes from the words 'multi' and 'media'. Multi means a lot, and media means a place, means or tool used to convey information. So based on the word 'multimedia' it can be formulated as a forum or the integration of several media which is then defined as elements of multimedia formation. These elements, such as text, images, sound, animation, and video. Multimedia is a new concept and technology in the field of information technology, where information in the form of text, images, sound, animation, and video is put together in a computer to be stored, processed and presented both liner and interactive. By combining all these multimedia elements, information in the form of multimedia can be received by the senses of sight and hearing, closer to the original form in the real world. Interactive multimedia is when an application contains all existing multimedia elements, and users are given a decision or ability to guard and turn on these elements. 


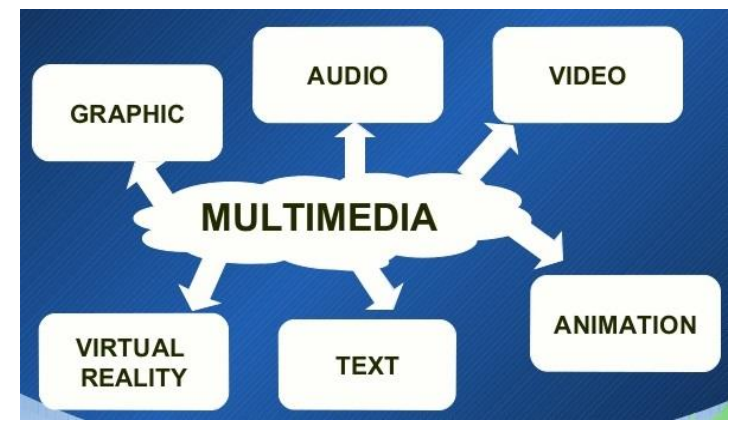

Fig.1. Multimedia Elements

\section{Effectiveness Of Learning Media}

There are several criteria for assessing the effectiveness of a media. Hubbard proposed nine criteria for assessing its (Hubbard, 1983). The first criteria is cost. Costs must be assessed by the results that will be achieved with the use of the media. Other criteria are the availability of supporting facilities such as electricity, compatible with class size, brevity, ability to be changed, time and energy of preparation, the effect caused, complexity and the latter are used. The more learning goals that can be helped by a media, the better the media. The above criteria are more intended for conventional media. Thorn proposed six criteria for assessing interactive multimedia (Thorn, 1995). The first assessment criteria are ease of navigation. A program must be designed as simple as possible so that language learners do not need to learn computers first. The second criterion is the content of cognition, the other criteria is knowledge and presentation of information. Both of these criteria are to assess the content of the program itself, whether the program has met the learning needs of the learner or not. The fourth criterion is media integration where the media must integrate language aspects and skills that must be learned. To attract the interest of the learner the program must have an artistic appearance so that aesthetics is also a criterion. The last assessment criteria is the overall function. The program developer must provide the learning desired by the learner. So that when a person finishes a program he will feel he has learned something.

\section{Testing And Results}

For this research we have used android learning application as shown figure 2. 


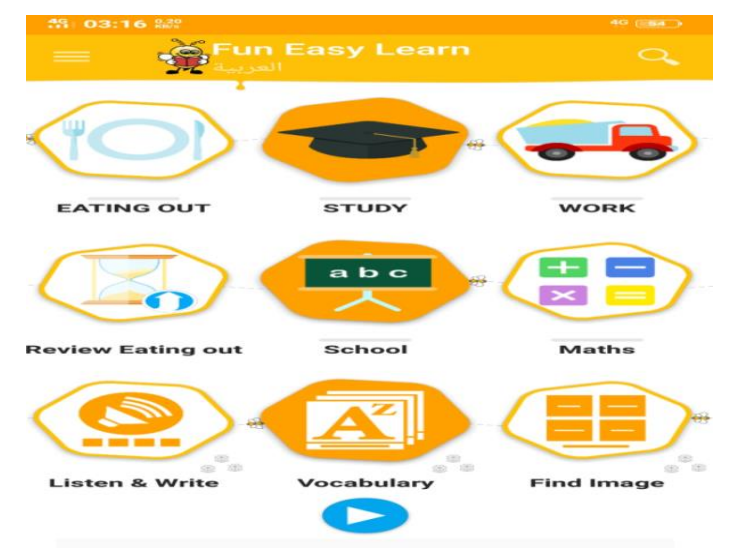

Fig. 2. Menu of Arabic Vocabulary Multimedia Learning

From the menu as shown figure 2, the user may tick the menu like "study" and then Arabic vocabulary will shown as figure 3 .

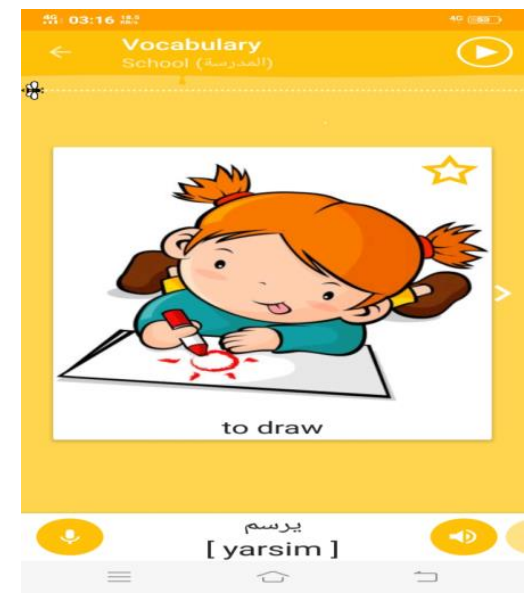

Fig.3. Example of Arabic Vocabulary

User can see what picture appears and hear the sound how to spell the vocabulary. Our research compares 20 students with ICT capability with 20 students have not ICT capability. And the result shown that users have the capability in ICT is easier for them to use the android learning application. So the multimedia learning android application is effective for student have ICT capability.

\section{Conclusions}

Learning media are needed to stimulate interest in learning. In this research, we have found that Multimedia-based learning media are very effective if used by students who are 
able to use ICT. So, if the student who are not able using ICT, then needs to train how to use theapplication.

\section{References}

[1]Briggs, Leslie J,. Instructional Design,Educational Technology Publications Inc. New Jersey : Englewood Cliffs, 1977.

[1]Brown, J.S., Collins, A. and DuGuid, P., Situated cognition and the culture of learning. Educational Researcher Jan.-Feb.: 32-42, 1989.

[1]Carl M Hubbard. 1983. Money Market Funds, Money Supply, and Monetary Control: A Note, The Journal of Finance Vol. XXXVIII, No. 4 September 1983.

[1]Nasution, Muhammad Irwan Padli, Abdul Hasan Saragih, Fun Mobile-Based Teaching Media for Primary School, Proceedings of the 2nd Annual International Seminar on Transformative Education and Educational Leadership (AISTEEL 2017), Advances in Social Science, Education and Humanities Research, Atlantis Press, 2017.

[1]Nasution, M. I. P., Andriana, S. D., Syafitri, P. D., Rahayu, E., \& Lubis, M. R., Mobile device interfaces illiterate. In Proceedings of the 2015 International Conference on Technology, Informatics, Management, Engineering and Environment, TIME-E 2015, 2016.

https://doi.org/10.1109/TIME-E.2015.7389758

[1]Nasution, Muhammad Irwan Padli, Aplikasi Pembelajaran Berbasis Mobile Untuk Tuna Aksara. MATICS: Journal Of Computer Science and Information Technology, 8 (1). pp. 11-16. ISSN 2477 2550, 2016,

[1]Thorn, Warwick J., Point to Consider when Evaluating Interactive Media. The Internet TESL Journal, Vol. II, No. 4.1995. 